\title{
Efektivitas Penggunaan Media Power Point Terhadap Hasil Belajar Matematika Materi Bangun Datar dan Bangun Ruang SD
}

\author{
Lionida Adhi Pramestika \\ Program Studi Pendidikan Guru Sekolah Dasar \\ Fakultas Keguruan dan Ilmu Pendidikan \\ Universitas Kristen Satya Wacana \\ Email:292017052@student.uksw.edu
}

\begin{abstract}
Abstrak
Penelitian ini bertujuan untuk mengetahui perbedaan hasil belajar Matematika siswa sekolah dasar yang dibelajarkan dengan media power point. Jenis penelitian yang digunakan adalah meta analisis dari penelitian yang telah dilakukan sebelumnya. Tujuan dari penelitian ini adalah untuk mengetahui pengaruh penggunaan media power point terhadap hasil belajar matematika materi bangun datar dan bangun ruang SD. Pengumpulan data dalam penelitian ini dilakukan dengan menelusuri jurnal melalui Google Cendekia. Kata kunci yang digunakan untuk penelusuran jurnal adalah efektivitas, pengaruh, media power point, hasil belajar matematika, materi bangun datar, bangun ruang, SD. Dari hasil pencarian tersebut dipilih 8 hasil penelitian untuk dianalisis lebih lanjut. Analisis menggunakan metode pembandingan untuk menentukan dampak penerapan media pembelajaran berbasis riset, selisih skor sebelum tindakan dengan sesudah tindakan sebagai besarnya peningkatan, kemudian dibagi dengan skor sebelum tindakan (dalam bentuk \%) untuk menentukan besarnya pengaruh tindakan pembelajaran terhadap hasil belajar. Peningkatan hasil belajar dari yang terendah $15 \%$ sampai yang tertinggi $83 \%$, dengan rata-rata $39 \%$. Rata-rata hasil belajar peserta didik sebelum penelitian tindakan kelas adalah 51,15 dan setelah dilakukan penelitian tindakan kelas dengan penerapan media power point pada pelajaran matematika materi bangun datar dan bangun ruang di SD terjadi peningkatan menjadi $81,15 \%$.
\end{abstract}

Kata kunci : Efektivitas, Power Point, Matematika, Bangun Datar, Bangun Ruang

\section{PENDAHULUAN}

Seiring perkembangan zaman yang terus terjadi dan berjalan dengan pesat mengakibatkan berbagai aspek kehidupan juga ikut berkembang untuk memenuhi tuntutan kehidupan yang ada. Salah satunya dalam bidang pendidikan yang terus berkembang seiring dengan perkembangan zaman dimana berbagai macam teknologi telah dikembangkan untuk meningkatkan mutu pendidikan. Teknologi yang digunakan merupakan modifikasi dari teknologi yang telah ada atau merupakan penemuan terbaru.

Salah satu kemampuan yang harus dimiliki oleh guru untuk meningkatkan minat belajar siswa yaitu guru dapat menguasai dan terampil dalam menggunakan berbagai media dalam proses pembelajaran. Djamarah (2008:213) mengatakan media adalah segala bentuk serta saluran untuk menyampaikan pesan maupun informasi. Untuk meningkatkan minat belajar siswa dapat menggunakan media pembelajaran seperti Microsoft Power Point. Microsoft Power Point adalah program aplikasi untuk membuat atau mengolah data presentasi. Data presentasi yang dapat dibuat berupa teks, tabel, grafik, gambar, bagan organisasi, dan sebagainya (Atang Gumawang, 2007:356). Microsoft Power Point ini bisa menghadirkan benda-benda untuk dijadikan contoh dalam bentuk gambar atau animasi yang lebih menarik dan berkesan, sehingga pembelajaran bisa dirasakan siswa lebih menyenangkan dan tidak membosankan dan mempercepat proses pembelajaran. Media power point ini dapat meningkatkan hasil belajar siswa. Lapono (2008: 1-12) mengemukakan bahwa hasil belajar diukur berdasarkan terjadi-tidaknya perubahan 
tingkah laku atau pemodifikasian tingkah laku yang lama menjadi tingkah laku yang baru. Seperti halnya dalam mata pelajaran matematika. Menurut Suriasumantri dalam Adjie (2006 : 34) menyatakan bahwa Matematika adalah salah satu alat berfikir, selain bahasa, logika, dan statistika. Matematika merupakan ilmu pengetahuan yang mempelajari tentang aljabar dan aritmatika atau geometri dan bangun ruang, bangun datar dan lain-lain. Pada mata pelajaran matematika media power point sangat diperlukan untuk melaksanakan pembelajaran. Khususnya pada materi bangun datar dan bangun ruang kita tidak perlu membawa barang tersebut. Kita bisa menggunakan media power point untuk menampilkan contoh bangun tersebut.

\begin{abstract}
Akan tetapi sebagian besar guru kurang menguasai dalam penggunaan media pembelajaran Microsoft Power Point. Masalah tersebut jika dibiarkan terus-menerus maka akan berdampak negatif pada kualitas belajar siswa. Siswa akan merasa bosan. Oleh karena itu, untuk mengatasi masalah tersebut perlu diadakan pembaharuan dalam proses belajar mengajar agar tujuan pembelajaran dapat tercapai. Dengan demikian, penulis bermaksud ingin membahas mengenai efektivitas penggunaan media power point terhadap hasil belajar matematika materi bangun datar dan bangun ruang di Sekolah Dasar.
\end{abstract}

\section{METODOLOGI PENELITIAN}

Pada penelitian ini menggunakan studi dokumen atas hasil-hasil penelitian yang sebelumnya sudah dilakukan. Dalam penelitian ini untuk pengumpulan datanya dilakukan dengan cara menelusuri jurnal pada media elektronik seperti digital library, internet, maupun koleksi jurnal perpustakaan.

Tabel 1. Besarnya Peningkatan Hasil Belajar Matematika Materi Bangun Datar dan Bangun Ruang sebagai Pengaruh Media Power Point

Penelusuran jurnal dilakukan melalui Google Cendekia. Kata kunci yang digunakan untuk penelusuran jurnal adalah: efektivitas, pengaruh, media power point, hasil belajar matematika, materi bangun datar, bangun ruang, SD.

Dari hasil pencarian tersebut dipilih 8 hasil penelitian untuk dianalisis lebih lanjut. Analisis menggunakan metode pembandingan untuk menentukan dampak penerapan media pembelajaran berbasis riset, selisih skor sebelum tindakan dengan sesudah tindakan sebagai besarnya peningkatan, kemudian dibagi dengan skor sebelum tindakan (dalam bentuk \%) untuk menentukan besarnya pengaruh tindakan pembelajaran terhadap hasil belajar.

\section{HASIL PENELITIAN DAN PEMBAHASAN}

Setelah melakukan pencarian pada google cendekia, diperoleh hasil penelitian seperti berikut ini. Dengan kata kunci efektivitas, pengaruh, media power point, hasil belajar matematika, materi bangun datar, bangun ruang, SD. Dari hasil penelusuran diperoleh 8 jurnal yang dipilih: Novia Ardianti (2013), Dewi Puji Rahayu, Kartika Chrysti Suryandari, dan Joharman (2013), Deny Irawan (2013), Evie Yunianti (2015), Muhtarom (2017), Nurul Hikmah (2017), Mirza Muhammad Iqbal (2020), Wahida Minfadhillah (2012). Mendasarkan hasil browsing yg dilakukan menggunakan Google Cendekia terseleksi seperti di atas, hasil analisis terkait efektivitas penggunaan media power point untuk meningkatkan hasil belajar matematika materi bangun datar dan bangun ruang SD dapat diperiksa pada tabel berikut ini:

Peningkatan Hasil Belajar

No Judul PTK Peneliti $\quad$ Semula Sesudah Gain $\begin{gathered}\text { Gain } \\ (\%)\end{gathered}$




\begin{tabular}{|c|c|c|c|c|c|c|}
\hline \multirow[b]{2}{*}{ No } & \multirow[b]{2}{*}{ Judul PTK } & \multirow[b]{2}{*}{ Peneliti } & \multicolumn{4}{|c|}{ Peningkatan Hasil Belajar } \\
\hline & & & Semula & Sesudah & Gain & $\begin{array}{c}\text { Gain } \\
(\%)\end{array}$ \\
\hline 1 & $\begin{array}{l}\text { Penggunaan Model Pembelajaran } \\
\text { Kontekstual dengan Media Power } \\
\text { Point dalam } \\
\text { Pembelajaran Peningkatan } \\
\text { Matematika di Kelas III Sekolah } \\
\text { Dasar }\end{array}$ & $\begin{array}{l}\text { Dewi Puji } \\
\text { Rahayu, } \\
\text { Kartika } \\
\text { Chrysti } \\
\text { Suryandari, } \\
\text { dan } \\
\text { Joharman. }\end{array}$ & 65,39 & 77 & 11,61 & 18 \\
\hline 2 & $\begin{array}{l}\text { Pemanfaatan Microsoft Power Point } \\
\text { pada Pembelajaran Luas Bangun } \\
\text { Datar untuk Meningkatkan Hasil } \\
\text { Belajar Siswa Kelas V }\end{array}$ & $\begin{array}{l}\text { Novia } \\
\text { Ardianti }\end{array}$ & 72,42 & 93,23 & 20,81 & 29 \\
\hline 3 & $\begin{array}{l}\text { Keefektifan Media Slide Presentasi } \\
\text { Terhadap Minat dan Hasil Belajar } \\
\text { Siswa pada Pembelajaran } \\
\text { Matematika Materi Bangun Datar di } \\
\text { Kelas III Sekolah Dasar Negeri 06 } \\
\text { Tegalsari Kabupaten Pemalang }\end{array}$ & Deny Irawan & 49,94 & 91,4 & 41,46 & 83 \\
\hline 4 & $\begin{array}{l}\text { Peningkatan Prestasi Belajar Siswa } \\
\text { Materi Keliling dan Luas Mata } \\
\text { Pelajaran Matematika melalui Media } \\
\text { Pembelajaran Powerpoint Interaktif } \\
\text { pada Siswa Kelas IV MI Islamiyah } \\
\text { Kauman Kidul Kota Salatiga Tahun } \\
2015\end{array}$ & Evie Yunianti & 68,12 & 84,54 & 16,42 & 24 \\
\hline 5 & $\begin{array}{l}\text { Penerapan Media Audio Visual } \\
\text { Macromedia Flash dan Power Point } \\
\text { untuk Meningkatkan Hasil Belajar } \\
\text { Matematika Siswa Sekolah Dasar }\end{array}$ & Muhtarom & 59,2 & 82,35 & 23,15 & 39 \\
\hline 6 & 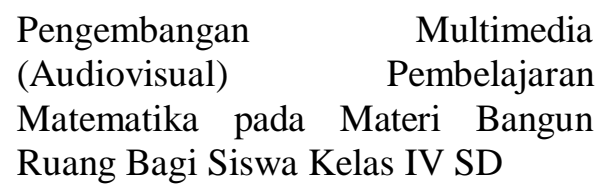 & $\begin{array}{c}\text { Nurul } \\
\text { Hikmah }\end{array}$ & 54,6 & 84 & 29,4 & 54 \\
\hline 7 & $\begin{array}{lrr}\text { Efektivitas } & \text { Strategi } & \text { Active } \\
\text { Knowledge Sharing dengan Media } \\
\text { Video Power Point Berbantuan } \\
\text { Screencast O Matic pada } \\
\text { Pembelajaran Bangun Ruang } \\
\text { Ditinjau dari Hasil dan Minat Belajar } \\
\text { Kelas V SD Ngadirejo 1 }\end{array}$ & $\begin{array}{l}\text { Mirza } \\
\text { Muhammad } \\
\text { Iqbal }\end{array}$ & 56,5 & 85 & 28,5 & 50 \\
\hline
\end{tabular}




\begin{tabular}{ccccccc}
\hline No & Judul PTK & Peneliti & \multicolumn{3}{c}{ Peningkatan Hasil Belajar } \\
& & Semula & Sesudah & Gain & $\begin{array}{c}\text { Gain } \\
(\%)\end{array}$ \\
\hline \multicolumn{2}{c}{ Komparasi Pengaruh } \\
$\begin{array}{l}\text { Sultimedia Power Point dan Media } \\
\text { Polyhedron terhadap Konsep } \\
\text { Matematika Bangun Ruang pada } \\
\text { Siswa Kelas IV Se-gugus Ki Hajar } \\
\text { Dewantara Karangtengah Wonogiri } \\
\text { Tahun Ajaran 2011//2012 }\end{array}$ & $\begin{array}{c}\text { Wahida } \\
\text { Minfadhillah }\end{array}$ & 65 & 75 & 10 & 15 \\
\hline Rata-rata Hasil Belajar Siswa & & $\mathbf{6 1 , 1 5}$ & $\mathbf{8 1 , 1}$ & $\mathbf{2 2 , 6 7}$ & $\mathbf{3 9}$ \\
\hline
\end{tabular}

Berdasarkan hasil analisis yang tersaji pada tabel di atas, dapat disimpulkan bahwa pembelajaran dengan media power point dapat meningkatkan hasil belajar peserta didik pada mata pelajaran matematika khususnya pada materi bangun datar dan bangun ruang di SD. Peningkatan hasil belajar dari yang terendah $15 \%$ sampai yang tertinggi $83 \%$, dengan ratarata 39\%. Rata-rata hasil belajar peserta didik sebelum penelitian tindakan kelas adalah 51,15 dan setelah dilakukan penelitian tindakan kelas dengan penerapan media power point pada pelajaran matematika materi bangun datar dan bangun ruang di SD terjadi peningkatan menjadi $81,15 \%$.

Kegiatan belajar dan pembelajaran di sekolah hendaknya dapat menciptakan terjadinya interaksi antara guru dengan siswa dan juga siswa dengan siswa (Wijayanti, 2016). Permasalahan yang terjadi di 8 sekolah dasar yang diteliti khususnya pada mata pelajaran matematika adalah kurangnya sarana dan prasarana di sekolah, kurangnya pemahaman guru dalam media pembelajaran yang modern, guru belum dapat melakukan dalam pemilihan strategi, metode, atau pendekatan yang tepat serta sesuai dengan materi yang akan diajarkan, cara guru mengajar yang masih menjelaskan materi di depan kelas, kurang menarik, serta keaktifan peserta didik dalam mengikuti pembelajaran masih kurang.

Seperti yang tersaji pada tabel di atas, pada penerapan media power point dapat meningkatkan hasil belajar peserta didik pada mata pelajaran matematika khususnya pada materi bangun datar dan bangun ruang di SD.
Menurut Alfian (2010:1) Power Point merupakan salah satu sarana yang populer karena kemudahan dan kelengkapan fiturfiturnya yang sangat mendukung dalam pembuatan sebuah presentasi yang baik.Menurut Alfian (2010:5) Kelebihan power point dalam kegiatan belajar mengajar adalah: (1) Mudah dan cepat dipahami oleh siswa, (2) Membantu guru memyampaikan isi pelajaran kepada siswa, (3) Mengefektifkan waktu dalam menyampaikan isi pelajaran, (4) Menarik minat dan perhatian siswa dalam materi yang disampaikan. Selain mempunyai kelebihan juga mempunyai kekurangan. Menurut Alfian ( 2010:6) Beberapa kekurangan power point dalam kegiatan belajar mengajar adalah: (1) Jika terlalu banyak animasi, grafik, bunyi-bunyian dan sebagainya dapat mengalihkan perhatian siswa terhadap materi yang diajarkan, (2) Membutuhkan waktu lama dalam pembuatan power point, (3) Pemilihan warna yang terlalu terang sebagai latar belakang slide dapat merusak indera penglihatan siswa, (4) Penggunaan power point dalam proses pengajaran dan pembelajaran bisa membuat pengajar hanya berbasis "show and tell" tanpa menerangkan isi pengajaran, (5) Jika terjadi pemadaman listrik, maka pembelajaran dengan menggunakan media Microsoft Power Point tidak dapat dilaksanakan pada hari itu.

\section{SIMPULAN}

Berdasarkan hasil analisis 8 jurnal mengenai efektivitas penggunaan media power point terhadap hasil belajar matematika materi bangun datar dan bangun ruang di Sekolah Dasar bahwa pentingnya menggunakan media 
pembelajaran dalam proses pembelajaran di sekolah agar siswa dapat memahami materi yang disampaikan oleh guru. Media power point juga dapat digunakan dalam proses pembelajaran. Mempelajari media Power Point ini juga mudah karena sering kita jumpai. Karena Microsoft Power Point ini merupakan salah satu program pengolahan data yang ada di laptop maupun komputer. Program Microsoft Power Point ini bisa menghadirkan benda-benda untuk dijadikan contoh dalam bentuk gambar atau animasi yang lebih menarik dan berkesan, sehingga pembelajaran bisa dirasakan siswa lebih menyenangkan dan tidak membosankan dan mempercepat proses pembelajaran.

Pada pembelajaran matematika khususnya pada materi bangun datar dan bangun ruang alangkah baiknya jika guru menggunakan media pembelajaran power point agar pada saat pelajaran siswa dapat lebih tertarik untuk memperhatikan gambar ataupun animasi yang ada pada slide presentasi. Sehingga dalam pembelajaran siswa tidak merasa mudah bosan. Pada media pembelajaran power point guru dapat mengembangkan model pembelajaran seperti menggunakan kuis untuk menarik perhatian siswa dalam mengerjakan latihan soal ataupun dapat dikembangkan menjadi berbagai hal lainnya yan mendukung proses kegiatan belajar.

\section{DAFTAR PUSTAKA}

Ardianti, N. (2013). Pemanfaatan Microsoft Power Point pada Pembelajaran Luas Bangun Datar untuk Meningkatkan Hasil Belajar Siswa Kelas V. Retrieved Portal Jurnal Ilmiah Universitas Tanjungpura, 3-14.

Hikmah, N. (2017). Pengembangan Multimedia (Audiovisual) Pembelajaran Matematika pada Materi Bangun Ruang bagi Siswa Kelas IV SD. Jurnal Pendas Mahakam, Vol. 4, No 2. 83-89.

Iqbal, Mirza Muhammad. (2020). Efektivitas Strategi Active Knowledge Sharing dengan Media Video Power Point Berbantuan Screencast O Matic pada Pembelajaran Bangun Ruang Ditinjau dari Hasil dan Minat Belajar Kelas V SD Ngadirejo 1. Retrieved Electronic Theses and Dissertations Universitas Muhammadiyah Surakarta

Irawan, Deny. (2013). Keefektifan Media Slide Presentasi Terhadap Minat dan Hasil Belajar Siswa pada Pembelajaran Matematika Materi Bangun Datar di Kelas III Sekolah Dasar Negeri 06 Tegalsari Kabupaten Pemalang. Retrieved DIGILIB UNNES:

Minfadhillah, Wahida. (2012). Studi Komparasi Pengaruh Multimedia Power Point dan Media Polyhedron terhadap Konsep Matematika Bangun Ruang pada Siswa Kelas IV Se-gugus Ki Hajar Dewantara Karangtengah Wonogiri Tahun Ajaran 2011//2012. Retrieved UPT Perpustakaan Universitas Sebelas Maret:

Muhtarom. (2017). Penerapan Media Audio Visual Macromedia Flash dan Power Point untuk Meningkatkan Hasil Belajar Matematika Siswa Sekolah Dasar. 145-154. Jurnal Pendidikan dan Pembelajaran Sekolah Dasar. Vol. 4, No 2.

Rahayu, Dewi Puji., Suryandari, Kartika Chrysti., \& Joharman. (2013). Penggunaan Model Pembelajaran Kontekstual dengan Media Power Point dalam Peningkatan Pembelajaran Bangun Datar Matematika Di Kelas III Sekolah Dasar. Retrieved Kalam Cendekia PGSD Kebumen

Yunianti, Evie. (2015). Peningkatan Prestasi Belajar Siswa Materi Keliling dan Luas Mata Pelajaran Matematika melalui Media Pembelajaran Powerpoint Interaktif pada Siswa Kelas IV MI Islamiyah Kauman Kidul Kota Salatiga Tahun 2015. Retrieved IAIN SALATIGA 